\title{
Evolutionary morphology of the rabbit skull
}

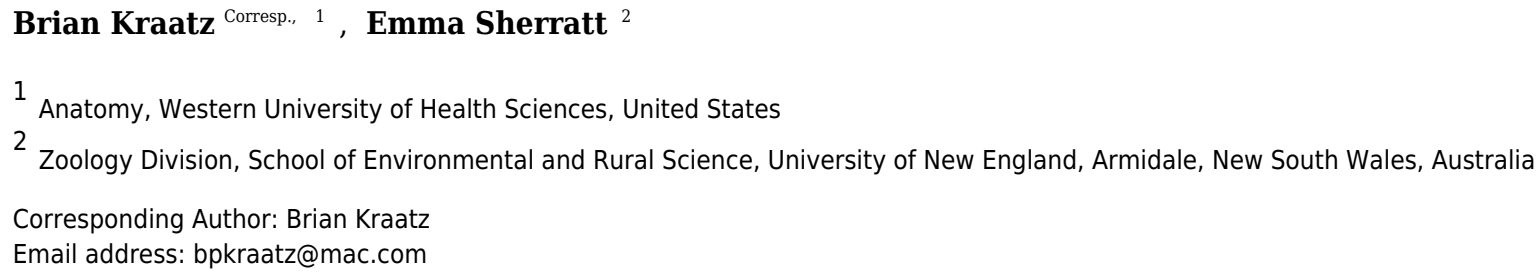

The skull of leporids (rabbits and hares) is highly transformed, typified by pronounced arching of the dorsal skull and ventral flexion of the facial region (i.e., facial tilt). Previous studies show that locomotor behavior influences aspects of cranial shape in leporids, and here we use an extensive 3D geometric morphometrics dataset to further explore what influences leporid cranial diversity. Facial tilt angle, a trait that strongly correlates with locomotor mode, significantly predicts the cranial shape variation captured by the primary axis of cranial shape space, and describes a small proportion (13.2\%) of overall cranial shape variation in the clade. However, locomotor mode does not correlate with overall cranial shape variation in the clade, because there are two district morphologies of generalist species, and saltators and cursorial species have similar morphologies. Cranial shape changes due to phyletic size change (evolutionary allometry) also describes a small proportion (12.5\%) of cranial shape variation in the clade, but this is largely driven by the smallest living leporid, the Pygmy rabbit (Brachylagus idahoensis). By integrating phylogenetic history with our geometric morphometric data, we show that the leporid cranium exhibits weak phylogenetic signal and substantial homoplasy. Though these results make it difficult to reconstruct what the 'ancestral' leporid skull looked like, the fossil records suggest that dorsal arching and facial tilt could have occurred before the origin of the crown group. Lastly, our study highlights the diversity of cranial variation in crown leporids, and highlights a need for additional phylogenetic work that includes stem (fossil) leporids and includes morphological data that captures the transformed morphology of rabbits and hares. 
1

$4 \quad{ }^{1}$ Department of Anatomy, College of Osteopathic Medicine of the Pacific, Western University of 5

\section{EVOLUTIONARY MORPHOLOGY OF THE RABBIT SKULL}

Brian Kraatz ${ }^{1}$ \& Emma Sherratt ${ }^{2}$

Health Sciences, Pomona, CA, 91766 USA

${ }^{2}$ Department of Evolution, Ecology and Genetics, Research School of Biology, The Australian National University, Canberra, ACT, 2601 Australia

8

SHORT TITLE:

Corresponding author: Brian Kraatz

College of Osteopathic Medicine of the Pacific

Western University of Health Sciences

309 East $2^{\text {nd }}$ Street

Pomona, CA 91711

Email: bkraatz@westernu.edu

Phone: (909) 706-3835

\section{8}




\section{ABSTRACT}

25

26 The skull of leporids (rabbits and hares) is highly transformed, typified by pronounced arching of

27 the dorsal skull and ventral flexion of the facial region (i.e., facial tilt). Previous studies show

28 that locomotor behavior influences aspects of cranial shape in leporids, and here we use an

29 extensive 3D geometric morphometrics dataset to further explore what influences leporid cranial

30 diversity. Facial tilt angle, a trait that strongly correlates with locomotor mode, significantly

31 predicts the cranial shape variation captured by the primary axis of cranial shape space, and

32 describes a small proportion $(13.2 \%)$ of overall cranial shape variation in the clade. However,

33 locomotor mode does not correlate with overall cranial shape variation in the clade, because

34 there are two district morphologies of generalist species, and saltators and cursorial species have

35 similar morphologies. Cranial shape changes due to phyletic size change (evolutionary

36 allometry) also describes a small proportion (12.5\%) of cranial shape variation in the clade, but

37 this is largely driven by the smallest living leporid, the Pygmy rabbit (Brachylagus idahoensis).

38 By integrating phylogenetic history with our geometric morphometric data, we show that the

39 leporid cranium exhibits weak phylogenetic signal and substantial homoplasy. Though these results make it difficult to reconstruct what the 'ancestral' leporid skull looked like, the fossil

41 records suggest that dorsal arching and facial tilt could have occurred before the origin of the

42 crown group. Lastly, our study highlights the diversity of cranial variation in crown leporids, and

43 highlights a need for additional phylogenetic work that includes stem (fossil) leporids and

44 includes morphological data that captures the transformed morphology of rabbits and hares. 
Though there exists a clear functional relationship between the vertebrate skeleton and

locomotion, there are more limited examples of how the skull (cranium and mandible complex)

may relate to movement. Strong associations between cranial form and locomotion are rare among vertebrates (Wake, 1993), however, the correlation between basicranial flexion and bipedal locomotion within our own lineage has been extensively studied (see Lieberman et al., 2000 , for a thorough review). In a far less studied system, the morphological transformations of the leporid (rabbits and hares) cranium are in many ways similar to those of anthropoid basicranial flexion (DuBrul, 1950, but see Moore and Spence, 1969; Jeffery and Cox, 2010 for further discussion). Both hominid and leporid skulls represent conditions in which the basicranial and facial regions of the cranium flex ventrally relative to one another, where the basicranium is considered the flexor in hominids, and the facial region as the flexor in leporids. While these cranial transformations have been extensively explored as they relate to locomotion in hominins, and briefly within leporids (White and Keller, 1984; Bramble, 1989), given the similarity in cranial transformations between these groups, rabbits and hares represent an ideal system to further understand the relationship between cranial form and locomotor function.

In a previous study, we described the ventral flexion of the cranial face in leporids as facial tilt (Kraatz et al., 2015). Leporids exhibit pronounced dorsal arching of the cranial roof as the facial region reflects ventrally relative to the basicranium (Fig. 1). In their radiographic study, Vidal et al. (1986) demonstrate the facial cranium of Oryctolagus cuniculus is tilted ventrally relative to the basicranium in resting position, which was also discussed by De Beer (1947). Though this condition is previously described qualitatively with regard to Oryctolagus (Thompson, 1942; DuBrul, 1950; De Beer, 1947), we used angular measurements (e.g., Fig. 1) to demonstrate that the degree of facial tilt strongly varies among a wide range of living leporid 
70 species (Kraatz et. al, 2015). Most strikingly, our previous study also showed that the degree to

71 which leporids faces tilt ventrally is strongly correlated to locomotor style. Leporid species with

72 skulls that have limited facial tilt (high angles) are more likely to exhibit generalist locomotory

73 modes (less hopping, at slower speeds) and that those with pronounced facial tilt (low angles) are

74 more cursorial (high speed hopping) (Kraatz et al., 2015).

75

Measuring ventral flexion as a simple facial tilt angle may show strong predictive value because it records relative changes in position between distinct regions of the cranium (i.e., splanchnocranium and neurocranium; Kraatz et al., 2015). However, such a simple measurement likely oversimplifies the complex shape changes and structural rearrangements of the cranium related to facial tilt. Therefore, a robust, geometric morphometric approach is needed characterize the complex geometry (shape) of the cranium and understand how overall cranial shape impacts upon morphological disparity and relates to function. In this paper we build upon our previous finding that shows facial tilting appears to be a major trait driving leporid cranial functional morphology (Kraatz et al., 2015) and turn our attention to better understanding the highly-transformed nature of the leporid skull by taking a geometric morphometric approach to study the shape variation across leporids. Our aim is to capture the complexity of leporid cranial shape among species, examine its relationship to the simple angular measure of facial tilt and thus locomotion, and examine its evolutionary history more broadly. To this end, we have compiled a three-dimensional landmark-based data set digitized on micro CT-scanned crania with the goals to 1) expand our taxonomic coverage to better capture the diversity of crown leporids (Table 1),2) conduct a robust (geometric morphometric) exploration of shape among leporids, 3) use molecular hypotheses of leporid evolution to examine how the highly transformed leporid skull evolved, particularly in relation to locomotion and also evolutionary 
93 size change (evolutionary allometry), and 4) quantitatively describe the complex morphological

94 changes associated with facial tilt and assess the contribution of facial tilt to leporids cranial

95 morphospace.

96 With these data we can explicitly test how cranial shape is driven by allometry,

97 locomotor mode, and facial tilt angle (sensu Kraatz et al., 2015). If angular leporid facial tilt is a

98 biologically-relevant trait that records changes in the facial region relative to the basicranium, we

99 expect that overall dorsal arching of the cranial roof to represent a close proxy for angular facial

100 tilt, and therefore have a strong overall influence on cranial disparity. Our landmark scheme (Fig.

101 2; Table 2) was developed capture this trait, although we have also measured angular facial tilt

102 via our landmark data that closely matches previous angular measurements of facial tilt. We

103 expect that skull roof dorsal arching and relative facial ventral flexion will load heavily on our

104 first principal component axis, and be strongly correlated to angular facial tilt. If facial ventral

105 flexion remains a dominant trait, and loads heavily on PC 1, we also predict that both will

106 strongly associated with locomotor mode among leporids. Finally, given that a lack of facial tilt

107 is a primitive condition for placental mammals and stem-lagomorphs (Asher et al., 2005), we

108 expect that our analyses estimating the evolutionary history of the leporids cranium will show

109 that increased facial tilt is a derived condition within crown Leporidae. 


\section{METHODS}

\section{Samples and $x$-ray micro-CT}

114 We sampled 184 leporid crania spanning 20 species (Table S1), including all 11 living

115 genera of Leporidae. Species were chosen based on museum availability and to cover a breadth

116 of the known diversity, while establishing sufficient coverage of the two most speciose genera,

117 Sylvilagus and Lepus, and to best match the taxonomic coverage in the molecular phylogeny of

118 Matthee et al. (2004). To capture within-species variation, all efforts were made to include at

119 least 10 crania of each species, although for some rare taxa this was not possible. Only adults

120 were sampled, which were aged based on the degree of osteological fusion in the occipital

121 complex (Hoffmeister and Zimmerman, 1967). The crania (dry skeletal material without

122 mandibles) were scanned using x-ray micro computed tomography (micro-CT) by J. Morita

123 using a Veraviewepacs 3D R100 system (typically, 70kv, 3mA) with voxel size ranging from

$124 \quad 125-160 \mu \mathrm{m}$.

125

126 Morphometric analyses

127 We characterized the shape of the 184 crania using landmark-based geometric

128 morphometrics (Bookstein 1991; Mitteroecker and Gunz 2009). We thresholded each scan to

129 obtain a 3D reconstructed model of the cranium and digitized 52 landmarks using the software

130 Checkpoint (Stratovan Corporation, Davis, CA) (Figure 2; Table 2); 44 of these are landmarks

131 placed at homologous points on the cranium, over the left and right sides, and 8 are equally-

132 spaced semilandmarks placed along the sagittal axis of the cranial roof to capture the curvature

133 of the dorsal arch of the cranium. This curve of semilandmarks is homologous in all specimens

134 and used to capture the changes in geometry of the cranial roof, an area which is highly variable 
135 among living leporids (Kraatz et al., 2015). Coordinate data for each specimen were exported as

136 individual Morphologika files, which are entirely available as a combined, compressed

137 supplemental file.

138 All of the statistical analyses were completed in $R$ (R Development Core Team) using the

139 package geomorph v.3.0.1 (Adams and Otárola-Castillo 2013; Adams et al. 2016). Of the 184

140 crania, 39 specimens were missing some landmarks, typically reflecting breaks in zygomatic

141 arches, supraorbital process, or regions of the basicranium (denoted in the Morphologika files as

142999999999999 coordinates). Missing landmarks were estimated with geomorph using a

143 multivariate regression approach, where each missing landmark is predicted based on a

144 regression among all other homologous landmarks of complete specimens within the data (Gunz

145 et al. 2009). The missing landmarks for each specimen are summarized in Table S2. The

146 landmark data were aligned using a generalized Procrustes superimposition (Rohlf and Slice

147 1990), taking into account object symmetry, resulting in shape variables for the symmetric

148 component of shape (Klingenberg et al. 2002). During Procrustes superimposition the cranial

149 roof semilandmarks were permitted to slide along their tangent directions in order to minimize

150 Procrustes distance between specimens (Gunz et al. 2005). The resulting symmetric shape data

151 are used in the following analyses.

\section{Phylogenetic hypothesis}

153 In order to examine cranial shape and factors influencing leporid cranial shape variation

154 in a phylogenetic context, we used the phylogenetic relationships among species of Leporidae

155 recently published by Matthee et al. (2004). The original tree was constructed using seven genes

156 (five nuclear and 2 mitochondrial) for 25 ingroup taxa. The tree was pruned to include only the

15720 species studied here (Table 1) using Mesquite (Maddison \& Maddison, 2015). 


\section{Principal components analysis and phylomorphospace}

The variation in cranial shape across all 184 specimens was first examined using

161 Principal Components Analysis (PCA) of the symmetric shape data. Shape changes from the

162 mean shape of the sample described by each PC axis were visualized using a surface warp

163 approach (e.g. Drake and Klingenberg 2010; Sherratt et al. 2014), which uses the thin-plate

164 spline (TPS) method (Bookstein 1989). We took a triangular surface mesh (obtained from

165 thresholding the CT scan for bone) of a specimen (Lepus americanus, LACM 70392, Table S1)

166 close to the mean shape and warped it to the mean shape using TPS. Then we warped the mean

167 shape mesh to the shapes represented by the minima and maxima of the first four PC axes.

168 A PCA of the species mean shapes was used to obtain a low-dimensional presentation of

169 the leporid cranial morphospace, into which the phylogenetic tree was projected to estimate the

170 evolutionary history of cranial shape change. We used maximum-likelihood ancestral state

171 estimation to estimate the PC scores representing the internal nodes of the tree (using fastAnc in

172 R package: phytools, Revell 2012). The resulting phylomorphospace (sensu Sidlauskas 2008)

173 provides a visual representation of how the cranial shape of each species evolved in

174 morphospace. As our data set does not include fossil taxa, the ability of our phylomorphospace

175 analyses to reconstruct ancestral shape is limited. We discuss implications of the results with the 176 fossil record in the discussion.

177 The amount of phylogenetic signal in cranial shape was estimated using the multivariate $178 K$ statistic (Adams 2014a). The $K$ statistics provides a quantitative measure of the degree of

179 homoplasy in the shape data and complements the species patterns visualized in

180 phylomorphospace. A value of less than one implies that taxa resemble each other 
181 phenotypically less than expected under Brownian motion, and the test statistic is evaluated for

182 significance using a permutation procedure, whereby the variables are randomized relative to the 183 tree (Blomberg et al. 2003; Adams 2014a). We used 1000 permutations.

\section{Comparative statistical analyses}

186 Evolutionary allometry, the degree to which cranial shape variation among species is

187 evolutionarily associated with size variation (Klingenberg 1996), was examined using a

188 phylogenetic generalized least squares (PGLS) approach and the pruned molecular tree of

189 Matthee et al. (2004). The size of each cranium was estimated using the centroid size of the 3D

190 landmarks, which is calculated as the square root of the sum of squared distances of a set of

191 landmarks from their centroid (Dryden and Mardia 1998). We calculated species means of the

192 symmetric shape data and centroid size for the 20 species. A Procrustes distance PGLS (D-

193 PGLS) (Adams 2014b) was done on the species means shape data and the natural log of centroid

194 size. In this approach, significance testing is achieved by a permutation procedure, where the

195 shape data are shuffled across the tips of the phylogeny (using the Randomized Residual

196 Permutation Procedure; Collyer et al., 2015), repeated 1,000 times, and estimates of statistical

197 values are obtained and compared to the observed value.

198 We tested whether locomotor mode has an effect on cranial shape using a D-PGLS.

199 Locomotory ability of each species was classified as in Kraatz et al. (2015), except for that of

200 Romerolagus diazi, which was previously considered to be saltatorial. Additional literature

201 review reveals a generalist locomotor mode of Romerolagus, as described here, "It trots rather

202 than hops as other rabbits do." (Nowak, 1999, pg. 1726). We colored species in the PC1 vs. PC2 
203 morphospace by locomotor modes in order to visualize the morphospace occupation pattern 204 relative to these categories.

205 We calculated facial tilt angle using our landmark data to best approximate how it was 206 measured in our previous study (Kraatz et al., 2015): landmark 43 was the vertex, and we

207 calculated the angle between two imagined lines whose endpoints are landmarks 2 and 7 (Fig. 2).

208 First, we tested whether locomotor mode has an effect on facial tilt angle using a D-PGLS, to 209 verify the new approach to calculating facial tilt angle and also given we have sampled more 210 species than Kraatz et al. (2015). Then to understand how much facial tilt contributes to leporid

211 morphospace, we examined 1) how much of the shape variation along PC1 of the species-mean

212 PCA was attributed to facial tilt angle, and 2) how much of the total cranial shape variation was

213 predicted by facial tilt angle, using a D-PGLS in each case. To describe the cranial shape

214 changes associated with facial tilt, we performed a multivariate regression of the specimen

215 symmetric shape data and facial tilt angle and summarized the shape variation predicted by facial

216 tilt angle using the regression score (Drake \& Klingenberg 2010). Shape changes associated with

217 a shift from the mean shape to the most ventrally-flexed (low angle) and least ventrally-flexed

218 (high angle) were visualized using the surface warp approach, as described above for the PC 219 axes.

\section{RESULTS}

\section{Principal Component Analysis}

Cranial shape disparity within leporids is driven by several key traits that can be summarized in the first four principal component analyses (Fig. S1), which account for $64.2 \%$ of 
227 explained shape variation in our overall data set; all subsequent PCs each account for $5 \%$ or less

228 of the variation. Figures $3 \mathrm{~A}$ illustrate biplots of combinations of the first three principal axes.

229 The shape variation described by the first three axes is also summarized as warped crania

230 surfaces (Figs. 4, S2, \& S3), which are warps demonstrating the change from the mean shape to

231 the minima and maxima of each PC axis (for PC4 see Figs. S2, \& S3). The PCA suggests that

232 three primary morphogroups (I-III) exists in leporid morphospace, and they are demarcated in

233 Figure 3A (PC1 vs. PC2).

234 PC1 describes changes associated with dorsal arching of the cranial roof (i.e. facial tilt)

235 along the positive axis (Figs. 4, S2, \& S3). Variation in cranial dorsal arching among our

236 specimens is relatively continuous and strong throughout the entire data set. The positive axis of

$237 \mathrm{PC} 1$ is also associated with facial or diastemata elongation and a widening of the proximal

238 portion of the nasal bones. PC1 shows a reduction of bullae size towards the positive axis;

239 however, our limited landmark coverage of that area suggests this shape change should be

240 approached with caution. PC1 shows relatively continuous variation among our study group, but

241 also distinguishes morphogroups I and II. Brachylagus is recognized as a distinct morphogroup

242 due to separation along PC2 (see below). We note S. palustris as an outlier of morphogroup I,

243 which trends toward the most negative space of morphogroup I near a member of morphogroup

244 II (Caprolagus),. Morphogroup II, which includes Romerolagus, Pentalagus, Nesolagus, and

245 Caprolagus, clusters towards the negative portion of PC1. Within morphogroup I, all genera that

246 include multiple species (i.e, Lepus, Sylvilagus, and Pronolagus) show species discrimination

247 along PC1, and Pronolagus species are clearly separated by this axis.

248 Shape differences along PC2 are most strongly associated with relative proportions of the

249 basicranial and the facial regions (Figs. 4, S2, \& S3), where the basicranium is greatly enlarged 
250 relative to the facial region toward the positive end of PC2 as exemplified by Brachylagus. The

251 orbit is also enlarged, the palate shortened, and the caudal ends of the zygoma flare laterally

252 toward the positive portion of PC2. This axis strongly discriminates Brachylagus into a distinct

253 morphogroup III. PC2 also discriminates among species within morphogroup I; S. palustris, $S$.

254 obscurus, and S. audobonii show separation from a relatively more negative to more positive

255 position along PC2, respectively. Pronolagus spp. are also separated along PC2, and both

256 Bunolagus and Poelagus occupy distinct regions of morphospace within morphogroup I as

257 delineated via PC2.

258 Shape changes associated with the negative axis of PC3 (Figs. 4, S2) include diastemata

259 elongation, narrowing of interorbital width (via frontal bones), and caudal retraction of rostral

260 aspect of nasal bones. These shapes changes distinguish Pronolagus spp. from all other species

261 in morphogroup I, and Pronolagus rupestris is a distinct outlier among all species. PC3 also

262 separates species within both Sylvilagus and Lepus; neither of which, however, overlap with

263 Pronolagus within the morphospace of PC3. Along PC4 (Fig. S1-3), the basicranium becomes

264 narrower (as does the magnum foramen) and the supraoccipital processes extend caudally toward

265 the positive aspect of that axis. This component distinguishes species within Lepus moderately

266 well, which solely occupies the most positive aspect of PC4.

\section{Phylomorphospace}

The specimen PCA (Fig. 3A) and phylomorphospace (Fig. 3B, and S4 for a 3D

representation) reveal similar patterns of species occupation of morphospace and the main PC crania shape; branches connecting sister taxa within morphospace often stretch far along PC 
273 axes. Much of this is driven by morphogroup II (relatively flat-skulled leporids), which is

274 separated from the other morphogroups largely via PC1, yet most individuals within

275 morphogroup II have immediate sister relationships outside of that group. In concordance with

276 this pattern of homoplasy, we find there is no significant phylogenetic signal in cranial shape (K

$277=0.70, \mathrm{P}=0.148)$.

278

279

Factors influencing cranial shape: facial tilt, evolutionary allometry, and locomotory mode

Across all 20 species, there is significant evolutionary allometry in cranial shape (D-

PGLS, $\left.\mathrm{F}_{(1,18)}=2.57, \mathrm{P}=0.005\right) ; 12.5 \%$ of the variation in cranial shape is predicted by size.

However, the pattern we found is clearly driven by the smallest species, the pygmy rabbit

(Brachylagus idahoensis); excluding this species from the analysis revealed that only $7.7 \%$ of the

shape variation was predicted by size, and this cranial shape-size relationship was not significant

(D-PGLS, $\left.\mathrm{F}_{(1,17)}=1.42, \mathrm{P}=0.157\right)$. It is evident from the phylomorphospace, where points

representing species means have been plotted and scaled to average centroid size (scaled by

0.02), that evolutionary allometry is not driving the main axes of shape variation in leporids, since the different sized species are seemingly randomly distributed in morphospace (Fig. 3B). Locomotory mode does not predict overall cranial shape in these 20 species (D-PGLS, $\mathrm{F}_{(2,17)}=2.20, \mathrm{P}=0.076$ ). Overlaying the three locomotor categories to PC1 versus PC2 plot (Fig.

5, left inset, from Figure 3A) shows that generalist locomotors are strongly discriminated from both saltators and cursorial species along PC1. Generalists occupy only the negative portions of PC1, and show no overlap with cursorial taxa along that axis, yet there are two distinct groups of generalists, discriminated along PC2. All saltatorial and cursorial species are found within 
296 Sylvilagus, S. palustris is the only species that exhibits a generalist form of locomotion and that

297 species occupies the most negative space along PC1 for that genus, and the most negative space 298 along PC1 for morphogroup I.

299 Facial tilt angle explains $21.6 \%$ of shape variation described by the first PC axis (PC1, D-

300 PGLS, $\left.F_{(1,18)}=4.96, P=0.03\right)$, and $13.2 \%$ of the overall cranial shape variation among all 20

301 species $\left(\mathrm{D}-\mathrm{PGLS}, \mathrm{F}_{(1,18)}=2.69, \mathrm{P}=0.013\right)$. We show the relationship between facial tilt and

302 overall cranial shape in Fig. 6 using a multivariate regression; the regression score is a univariate

303 summary of the highly multivariate shape changes associated with the independent variable, and

304 thus can be thought of as an axis through morphospace that relates to variation in facial tilt angle.

305 The shapes changes most strongly related to changes in facial tilt include dorsal cranial arching

306 and relative size changes between the basicranium and facial regions (Fig. 6). Incidentally, the

307 regression score and $\mathrm{PC} 1$ are highly correlated (linear regression, $\mathrm{r}^{2}=0.921$ ), signifying that the

308 main axis of cranial variation in leporids (i.e. PC1) is strongly associated with dorsal arching and 309 facial tilt.

310 Given locomotor mode does not predict cranial shape, but facial tilt does, it is noteworthy

311 that we find these two factors to be themselves related. That is, in accordance with previous

312 findings by Kraatz et al. (2015), facial tilt angle is correlated with locomotor mode (D-PGLS,

$\left.313 \mathrm{~F}_{(2,17)}=11.13, \mathrm{P}=0.003\right)$, where lower facial tilt angle, meaning more pronounced cranial

314 flexion, is found in cursorial species, and high angles are found in generalist species (Figs. 5, 315 S5).

\section{DISCUSSION}



influences on the overall cranial shape of crown leporids, and that these influences are at least

321 partially driven by ecological factors. The primary axis of leporid morphospace (PC1)

322 characterizes a major portion of overall cranial shape variation among extant leporids (Fig. 4,

$32326.7 \%$ ), and though several trait changes load strongly on that axis, this is the only PC axis that

324 clearly highlights changes in both dorsal arching and facial tilt. We also show that facial tilt angle significantly explains one seventh of cranial shape among leporid species, and directly contributes to the shape differences along PC1.

Our analyses showed more mixed results with regard to the influence of allometric size changes on cranial shape. Although we found that there are significant differences in cranial shape associated with allometric size changes, this is largely driven by the smallest of living leporids, the Pygmy rabbit (Brachylagus idahoensis). The influences of the Pygmy rabbit on allometric size changes are clearly a product of both its small size and unique overall cranial shape (Fig. 3). Brachylagus is isolated in morphospace, and strongly summarizes variation along PC2 due to its large basicranium region relative to its facial region. As demonstrated in many mammal lineages, as body size increases, the facial regions typically increase in size relative to basicrania (Cardini and Polly, 2013; Cardini, et al., 2015). The short-faced Brachylagus is likely an excellent example of heterochronic changes within leporids that warrants further study. that recognizes the need to quantitatively investigate the greatly underappreciated morphological

339 disparity of the leporid skeleton. Certainly for taxonomic purposes linear measurements play an

340 important role in delineating species (e.g. Palacios et al., 2008; Pintur et al., 2014). The

341 laboratory model species Oryctolagus cuniculus has been extensively studied to understand 
342 pathologies of craniogenesis as they relate sutural synostosis (e.g., Burrows, et al., 1999). White

343 and Keller (1984) conducted a linear morphometric study to understand the ecomorphology of

344 the North American lagomorph skull, and found evidence for three ecomorphs, which

345 correspond to habit preferences, which we also recovered (and discussed further below). Our

346 study particularly complements the 2D geometric morphometric analyses of postnatal growth

347 changes and cranial disparity within leporids (Ge et al., 2012; Zhang and Ge, 2014; Ge et al.,

348 2015), which showed postnatal ontogenetic growth involves changes in the relative size of the

349 basicranial and facial regions. Our findings align with those of Ge et al. (2015) who also found

350 little phylogenetic signal within leporid morphospace, and high levels of homoplasy. Together,

351 these studies and ours demonstrate to the broader audience the unappreciated complexity of the

352 leporid cranium and highlight the need to investigate further what evolutionary and

353 developmental factors have contributed to the morphological diversity of rabbits.

\section{Implications of leporid facial tilt angle and associated cranial shape changes}

Locomotor mode influences significant aspects of cranial shape, namely the degree of

facial tilt and dorsal arching. Here we show that overall cranial shape, particularly PC1 of leporid

morphospace, is highly correlated to facial tilt angle. Our previous facial tilt angle measurement

(Kraatz et al., 2015) was found to be significantly different between generalist locomotors and species that were saltators/cursors. Here we show that overall cranial shape, particularly PC1 of

361 leporid morphospace, is highly correlated to facial tilt angle. Though this broad relationship

362 between form and function is clear among leporid crania, the two most speciose genera, Lepus

363 and Sylvilagus, each present important examples of this relationship at a more refined taxonomic

364 level. 
366 linear measurements to show that cranial morphology describes three ecomorphs among North

367 American lagomorphs (rabbits, hares, and pikas), irrespective of taxonomic relationships. Their

368 study identifies rock rabbit (ochotonid, pikas), cottontail, and jack rabbit ecotypes, and points

369 out that the Snowshoe Hare (Lepus americanus), while taxonomically a hare (Lepus), functions

370 as a rabbit, and indeed, morphological groups with cottontails. We identify a very similar pattern

371 within our data set, where L. americanus groups in the most negative space along PC1 among all

372 Lepus species and most species of Morphogroup I (Fig. 3). As we have shown that PC1 is

373 correlated with facial tilt, which itself predicts locomotor mode, there seems to be a clear change

374 in cranial shape within L. americanus that is likely related to the fact that it ecologically

375 resembles cottontails. The Marsh rabbit (Sylvilagus palustris) represents a similar case within

376 Sylvilagus, as $S$. palustris is known to have hind- and forelimbs that are roughly the same length

377 and does not exhibit the typical hopping observed in cottontails (Chapman and Ceballos, 1990).

378 As with L. americanus, S. palustris groups within the most negative space along PC1 among

379 Sylvilagus species, and is more closely positioned to Morphogroup II than any other species

380 within Morphogroup I (Fig. 3). The relative morphospace placement of L. americanus and $S$.

381 palustris among closely related species suggests that there exists plasticity in cranial shape as it

382 relates to function even within leporid genera, and strongly confirms the ecomorphs initially

383 identified by White and Keller (1984).

384 Though the facial tilt of leporids described in this study is not typical for the mammalian

385 skull, this type of ventral flexion of the cranium is known from other mammalian groups. DuBrul

386 (1950, plate 6), in his discussion of cranial arching in lagomorphs, contrasts parallel

387 transformations in South American caviid rodents. He notes that the relatively flat-skulled, pika- 
388 like guinea pig (Cavia) is less facially tilted than the rabbit-like Mara (Dolichotis), and given that

389 guinea pigs are not cursorial and maras are, the correspondence between facial tilt and

390 locomotion seems relevant in other closely related groups. Spencer (1995) showed that African

391 bovids that preferentially fed on grasses have increased basicranial flexion; and in a 3D

392 geometric morphometric study, Merino et al. (2005) showed differences in basicranial flexion

393 among cervids. Drake (2011) notes differences in basicranial flexion of dogs as compared to

394 wolves, and Wroe and Milne (2007) show differences in basicranial flexion between marsupial

395 and placental carnivores. Although these studies have shown similar examples of ventral flexion

396 in crania, few have shown such a high degree of correlation with ecological variables, such

397 pronounced ventral flexion, or such a significant influence on overall cranial disparity as shown

398 here for leporids. Perhaps the only parallel of scale is that of anthropoids, which also show many

399 of these features that are likely related to locomotor mode (DuBrul, 1950; Lieberman et al.,

400 2000). Basicranial flexion in hominids clearly relates to bipedal locomotion, but other factors,

401 such as brain size increase (Ross et al., 2004) may also influence this trait. As we discussed

402 previously (Kraatz et al., 2015), facial tilt in leporids also has the consequence of increasing

403 orbital frontation that may allow for better visualization of the substrate during high-speed

404 locomotion. While facial tilt is functionally predictive, it does not completely explain cranial

405 shape, which us undoubtedly influenced by other important developmental, evolutionary, and

406 functional factors. Though we have identified that one seventh of shape variation among leporid

407 species is explained by facial tilt angle (and also a small but mostly not significant amount is due

408 to evolutionary allometry), this leaves a large proportion unexplained. These important

409 influences that drive evolutionary differences among leporids warrant further research. 
411 Inferring the evolutionary history of leporid cranial shape: insights from fossils

412 Understanding leporid cranial morphospace within the context of their evolutionary

413 history illustrates that the morphological 'root' of crown leporids (sensu Leporinae, Flynn et al., 414 2014) is unclear. Our phylomorphospace plots (Fig. 3B, Fig S4) show clearly that facial tilt is

415 strongly homoplastic within crown leporids. Using fewer species from our data set, we also

416 found the same homoplastic pattern using the molecular phylogeny of Ge et al. (2013; results not

417 shown). Ge et al. (2015) conducted a recent 2D geometric study of lagomorph crania and found a

418 similar pattern of homoplasy as it relates to cranial shape. Unfortunately, Ge et al. (2015) did not

419 report lateral views of crania, so much of the facial tilt and dorsal arching patterns discussed here 420 are not captured in that study.

$421 \quad$ Based on sister group relationships between each species in morphogroup II and 422 individuals in morphogroup I, reduced facial tilt is dispersed throughout crown leporids, and 423 therefore it has likely evolved multiple times (Figs. $3 \&$ 5). The ancestral node to all species in 424 this study is reconstructed very close to the origin of the phylomorphospace; this would produce 425 a cranium that is subtly flexed with a facial tilt angle around $50^{\circ}$ (average of the sample). But 426 such an "average skull" is unsurprising given that ancestral state reconstruction is a method of 427 weighted averaging, and the degree of homoplasy in cranial shape suggests that this method is 428 not appropriate to provide a window into the ancestral state of crown leporids. Instead, we must 429 look to the fossil to ask, did the ancestor of modern leporids have a flatter or more flexed facial 430 region?

431 Leporidae and Ochotonidae (pikas) represent the two living families of lagomorphs, and 432 recent fossil discoveries have revealed a detailed representation of stem-lagomorphs. At deeper 433 temporal levels, spanning to the base of the earliest stem-lagomorphs, the polarity of facial tilt is 
434 one of increasing flexion of the facial region (Fig. 7). This stem lineage divided into the two

435 modern families, but as discussed by DuBrul (1950), ochotonids show little facial tilt. Facial tilt

436 in the later stem-lagomorphs and stem leporids as gleaned from the fossil record, may allow us to

437 gain further insights into the origin of crown leporid cranial morphology.

438 The phylogenetic hypotheses of leporid evolution based on molecular evidence (Matthee

439 et al., 2004; Ge et al., 2013) are not generally congruent with morphological evidence; the latter

440 have been largely based on the morphology of the second and third premolars (Flynn, et al.,

441 2014, for a thorough discussion). Some recent studies have found more broad congruence

442 between molecules and morphology at the level of stem-lagomorphs (Asher et al., 2005, Wible,

443 2007), but there is not a clear picture of the evolutionary origin of crown leporids because there

444 is no comprehensive phylogenetic study that includes crown leporids, stem leporids, and stem

445 lagomorphs (see Flynn et al., 2014). Based on fossil teeth, it has been repeatedly suggested that

446 both Alilepus and Hypolagus are sister to crown leporids and are near the origin of that clade

447 (Dawson, 1981; Lopez-Martinez, 2008; Flynn et al., 2014). Though much of the fossil record of

448 leporids is based on partial maxillae, dentaries or isolated teeth, there are examples well-

449 preserved skulls of both Alilepus and Hypolagus that illustrate skull shape in what is most likely

450 the later stem-leporid lineage (Fig. 7). Both Alilepus hibbardi (White, 1991) and Hypolagus sp.

451 (Hibbard, 1969) represent stem-leporid species that show more facial tilt than some extant

452 lagomorphs, particularly those that fall into morphogroup II in our dataset (Fig. 3). Hibbard

453 (1969) described the significant dorsal arching of the cranium of Hypolagus sp., and noted that it

454 equals or exceeds that of any of the living leporids. In a morphometric study of the post-cranial

455 skeleton of the European H. beremendnesis, Fostowicz-Frelik (2007) showed that the limb

456 elongation of that species is comparable to that of highly cursorial extant leporid species. In 
457 short, various stem leporids had acquired a high degree of facial tilt that exceeds any measured in 458 extant species.

459

460 CONCLUSION

461

While a more comprehensive phylogenetic treatment that includes fossil taxa and better

462 coverage of stem-leporids is desperately needed, we can draw several important conclusions by 463 comparing our results to what we know of leporid cranial morphology from the fossil record. We

464 show here that facial tilt strongly influences the disparity of the leporid cranium, yet the

465 appearance of that trait likely occurred well before the radiation of the crown group. This,

466 however, does not clarify what the 'ancestral' crown leporid looked like. Though facial tilting

467 predates the crown diversification, it's unclear how that trait varied among and within stem-

468 leporid lineages. It remains entirely likely, for example, that facial tilt and locomotor mode

469 varied among Hypolagus or Alilepus species, as it does for living genera and species. Facial tilt is

470 a derived trait in the context of stem-lagomorphs; however, it seems clear that the lower degrees

471 of facial tilt within various crown leporids has been independently acquired from a more 'facially

472 tilted' stem-leporid ancestor, and that facial tilt is an adaptively plastic trait within the crown

473 group. Most importantly, a comprehensive, combined phylogenetic treatment of lagomorphs that

474 more explicitly covers stem leporids is badly needed. Such a treatment must thoroughly

475 incorporate morphological data beyond teeth, as the evolutionary history of leporids is marked

476 by remarkable and adaptively significant transformations of the skull.

477

\section{ACKNOWLEDGMENTS}

479

We would like to sincerely thank the many collections staff and museums that provided 
480 assistance and specimens for this study: Kawada Shin-ichiro, Department of Zoology, National

481 Museum of Nature and Science (Tsukuba, Japan;); Jim Dines, Department of Mammalogy,

482 Natural History Museum of Los Angeles County (USA); Eileen Westwig and Neil Duncan,

483 Department of Mammalogy, American Museum of Natural History (New York, USA); Esther

484 Langan and Darrin Lunde, National Museum of Natural History, Smithsonian Institution (USA);

485 Judith Chupasko, Department of Mammalogy, Museum of Comparative Zoology, Harvard

486 University (USA). Nicolas Bumacod provided important help in developing the protocol to

487 acquire geometric morphometric data. Assistance for CT scanning was provided by Dr. Bruno

488 Azevedo (University of Louisville) and Satareh Lavasani, and Alex Lee in WU's College of

489 Dental Medicine. Mathew Wedel provided thorough comments on an earlier version that greatly

490 improved this manuscript. Lily Li is sincerely thanked for allowing us to use her wonderful

491 original drawing of Ochotona in figure 6. I (BK) would especially like to thank Malcolm C.

492 McKenna (deceased) for giving me the rabbits from his Mongolian fossil collections 15 years

493 ago, when I asked for the insectivores, hyaenadontids, or the carnivores. He was right, people

494 need to work on rabbits.

495

496

\section{REFERENCES CITED}

497 Adams D. C. 2014a. A generalized K statistic for estimating phylogenetic signal from shape and 498 other high-dimensional multivariate data. Systematic Biology 63(5):685-697.

499

500 Adams D. C. 2014b. A method for assessing phylogenetic least squares models for shape and

501 other high-dimensional multivariate data. Evolution 68:2675-2688. 
503 Adams D. C, Collyer M. L., Sherratt E. 2016. geomorph: Software for geometric morphometric

504 analyses. R package version 3.0: cran.r-project.org/web/packages/geomorph/index.html.

505

506 Adams, D. C., and E. Otárola-Castillo. 2013. geomorph: an r package for the collection and

507 analysis of geometric morphometric shape data. Methods in Ecology and Evolution 4:393-399.

508

509 Asher RJ, Meng J, Wible JR, McKenna MC, Rougier GW, Dashzeveg D, Novacek MJ. 2005.

510 Stem Lagomorpha and the antiquity of Glires. Science 307(5712):1091-1094.

511

512 Blomberg S, Garland T Jr, Ives AR. 2003. Testing for phylogenetic signal in comparative data:

513 behavioral traits are more labile. Evolution, 57(4), pp.717-745.

514

515 Bookstein, F. L. 1989 Principal Warps: Thin-Plate Splines and the Decomposition of

516 Deformations. IEEE Transactions on Pattern Analysis and Machine Intelligence 11(6):567-585.

517

518 Bookstein, F. L. 1991. Morphometric tools for landmark data: Geometry and Biology.

519 Cambridge Univ. Press,, New York.

520

521 Bramble DM. 1989. Axial-appendicular dynamics and the integration of breathing and gait in 522 mammals. American Zoologist 29(1):171-186.

523

524 Burrows, A. M., Richtsmeier, J. T., Mooney, M. P., Smith, T. D., Losken, H. W., and Siegel, M.

525 I. 1999. Three-dimensional analysis of craniofacial form in a familial rabbit model of 
526 nonsyndromic coronal suture synostosis using Euclidean distance matrix analysis. The Cleft

527 Palate-craniofacial Journal, 36(3), 196-206

528

529 Cardini, A. and P.D. Polly. 2013. Larger mammals have longer faces because of size-related 530 constraints on skull form. Nature Communications, 4, art. 2458: 1-7.

531

532 Cardini, A., P.D. Polly, R. Dawson, and N. Milne. 2015. Why the long face? Kangaroos and 533 wallabies follow the same 'rule' of cranial evolutionary allometry (CREA) as placentals.

534 Evolutionary Biology, 42: 169-176

535

536 Chapman, J. A. and G. Ceballos. 1990. The Cottontails. In: Rabbits, hares and pikas. Status, 537 survey and conservation action plan. (J. A. Chapman and J. E. C. Flux, eds). Information Press, 538 Oxford: 95-110.

539

540 Collyer, M. L., D. J. Sekora, and D. C. Adams. 2015. A method for analysis of phenotypic

541 change for phenotypes described by high-dimensional data. Heredity 115:357-365. 542

543 Dawson, M. R. 1981. Evolution of the modern lagomorphs. In Proceedings of the World 544 Lagomorph Conference (K. Myers and CD MacInnes, Eds.) (pp. 1-8).

546 De Beer G. R. 1947. How animals hold their heads. Proceedings of the Linnean Society of 547 London 159(2):125-139. 
549 Drake, A. G., and C. P. Klingenberg. 2010. Large-scale diversification of skull shape in domestic

550 dogs: disparity and modularity. American Naturalist 175:289-301.

551

552 Drake, A. G. 2011. Dispelling dog dogma: an investigation of heterochrony in dogs using 3D

553 geometric morphometric analysis of skull shape. Evolution \& Development, 13(2), 204-213.

554

555 Dryden, I. L., and K. V. Mardia. 1998. Statistical shape analysis. Wiley, Chichester. pp.376.

556

557 DuBrul E. L. 1950. Posture, locomotion and the skull in Lagomorpha. American Journal of 558 Anatomy 87(2):277-313.

559

560 Flynn, L. J., A. J. Winkler, M. Erbaeva, N. Alexeeva, U. Anders, C. Angelone, S. Čermák, F. A.

561 Fladerer, B. Kraatz, and L. A. Ruedas. 2014. The Leporid Datum: a late Miocene biotic marker.

562 Mammal Review 44:164-176.

563

564 Fostowicz-Frelik, Ł. 2007. The hind limb skeleton and cursorial adaptations of the

565 Plio-Pleistocene rabbit Hypolagus beremendensis. Acta Palaeontologica Polonica 52 (3): 447566476.

567

568 Ge, D. Y., L v, X. F., Xia, L., Huang, C. M., Yang, Q. S. 2012. Geometric morphometrics of 569 postnatal size and shape changes in the cranium of cape hare (Lagomorpha, Leporidea, Lepus 570 capensis). Acta Theriologica Sinica. 32(1):12-24 
572 Ge DY, Wen ZX, Xia L, Zhang ZQ, Erbajeva M, Huang CM, Yang QS. 2013. Evolutionary

573 history of lagomorphs in response to global environmental change. PLoS ONE 8: e59668.

575 Ge DY, Yao L, Xia L, Zhang Z, Yang Q. 2015. Geometric morphometric analysis of skull

576 morphology reveals loss of phylogenetic signal at the generic level in extant lagomorphs

577 (Mammalia: Lagomorpha). Contributions to Zoology, 84 (4) 267-284

578

579 Gunz, P., P. Mitterocker, and F. L. Bookstein. 2005. Semilandmarks in three dimensions. Pp. 73-

58098 in D. E. Slice, ed. Modern morphometrics in physical anthropology. Kluwer

581 Academic/Plenum Publishers, New York.

582

583 Gunz, P., P. Mitteroecker, S. Neubauer, G. W. Weber, and F. L. Bookstein. 2009. Principles for

584 the virtual reconstruction of hominin crania. Journal of Human Evolution 57:48-62.

585

586 Hibbard, CW. 1969. The rabbits (Hypolagus and Pratilepus) from the upper Pliocene Hagerman

587 local fauna of Idaho. Michigan Academician 1:81-97.

Hoffmeister DF, Zimmerman EG. 1967. Growth of the skull in the cottontail (Sylvilagus

590 floridanus) and its application to age determination. American Midland Naturalist 78:198-206 
592 Jeffery N, Cox PG. 2010. Do agility and skull architecture influence the geometry of the

593 mammalian vestibulo-ocular reflex? Journal of Anatomy 216(4):496-509.

594

595 Klingenberg, C. P., \& Ekau, W. 1996. A combined morphometric and phylogenetic analysis of

596 an ecomorphological trend: Pela- gization in Antarctic fishes (Perciformes: Nototheniidae). Bio-

597 logical Journal of the Linnean Society, 59(2), 143-177.

598

599 Klingenberg, C. P., M. Barluenga, and A. Meyer. 2002. Shape analysis of symmetric structures:

600 quantifying variation among individuals and asymmetry. Evolution 56:1909-1920.

601

602 Kraatz, B. P., E. Sherratt, N. Bumacod, and M. J. Wedel. 2015. Ecological correlates to cranial 603 morphology in Leporids (Mammalia, Lagomorpha). PeerJ 3:e844.

604

605 Lieberman, D. E., Pearson, O. M., and Mowbray, K. M. 2000. Basicranial influence on overall 606 cranial shape. Journal of Human Evolution, 38(2), 291-315.

607

608 López-Martínez N. 2008. The lagomorph fossil record and the origin of the European rabbit. In:

609 Alves PC, Ferrand N, Hackländer K, editors. Springer-Verlag, Berlin, Heidelberg: Lagomorph

610 Biology: Evolution, Ecology and Conservation. pp. 27-46.

611

612 Maddison WP, Maddison DR. 2015. Mesquite: a modular system for evolutionary analysis.

613 Version 3.02 http://mesquiteproject.org

614 
615 Matthee, CA, Van Vuuren, BJ, Bell, D, Robinson, TJ. 2004. A molecular supermatrix of the 616 rabbits and hares (Leporidae) allows for the identification of five intercontinental exchanges 617 during the Miocene. Systematic Biology 53(3): 433-447.

618

619 Merino, M. L., Milne, N., and Vizcaíno, S. F. 2005. A cranial morphometric study of deer 620 (Mammalia, Cervidae) from Argentina using three-dimensional landmarks. Acta theriologica, $62150(1), 91-108$.

622

623 Mitteroecker, P., and P. Gunz. 2009. Advances in Geometric Morphometrics. Evolutionary 624 Biology 36:235-247.

625

Moore, W. J., and Spence, T. F. 1969. Age changes in the cranial base of the rabbit (Oryctolagus 627 cuniculus). The Anatomical Record, 165(3), 355-361.

628

629 Nowak, R. M. 1999. Walker's Mammals of the World (Vol. 1). Johns Hopkins University Press. 630

631 Palacios F, Angelone C, Alonso G, Reig S. 2008. Morphological evidence of species 632 differentiation within Lepus capensis Linnaeus, 1758 (Leporidae, Lagomorpha) in Cape 633 Province, South Africa. Mammalian Biology-Zeitschrift für Säugetierkunde 73(5):358-370. 634

635 Pintur K, Dančević N, Štedul I, Popović N, Slijepčević V. 2014. Craniometric features of 636 European hare (Lepus europaeus Pall.) from North-west Croatia and the island of Vir. 637 Veterinarski arhiv 84(4):387-400. 
639 R Development Core Team. 2016. R: a language and environment for statistical computing.

640 Vienna, Austria. Available online at http://www.R-project.org/.

641

642 Revell, L. J. 2012. phytools: an R package for phylogenetic comparative biology (and other 643 things). Methods in Ecology and Evolution 3:217-223.

644

645 Rohlf, F. J., and D. Slice. 1990. Extensions of the Procrustes Method for the Optimal

646 Superimposition of Landmarks. Systematic Zoology 39:40-59.

647

648 Ross, C. F., Henneberg, M., Ravosa, M. J., and Richard, S. (2004). Curvilinear, geometric and 649 phylogenetic modeling of basicranial flexion: is it adaptive, is it constrained? Journal of Human 650 Evolution, 46(2), 185-213.

651

652 Sidlauskas, B. 2008. Continuous and arrested morphological diversification in sister clades of 653 characiform fishes: a phylomorphospace approach. Evolution 62:3135-3156. 654

655 Sherratt, E., D. J. Gower, C. P. Klingenberg, and M. Wilkinson. 2014. Evolution of Cranial 656 Shape in Caecilians (Amphibia: Gymnophiona). Evolutionary Biology 41:528-545.

658 Spencer, L. M. 1995. Morphological correlates of dietary resource partitioning in the African 659 Bovidae. Journal of Mammalogy, 76(2), 448-471. 
661 Thompson, D. W. 1942. On growth and form. $2^{\text {nd }}$ Ed. New York: Macmillan.

662

663 Vidal PP, Graf W, Berthoz A. 1986. The orientation of the cervical vertebral column in

664 unrestrained awake animals. Experimental Brain Research 61:549-559.

665

666 Wake MH. 1993. The skull as a locomotor organ. In: Hanken J, Hall BK, editors. The Skull,

667 volume 3: Functional and Evolutionary Mechanisms. Chicago: University of Chicago Press, 197668240.

669

670 White, JA. (1991). North American Leporinae (Mammalia: Lagomorpha) from late Miocene 671 (Clarendonian) to latest Pliocene (Blancan). Journal of Vertebrate Paleontology, 11(1), 67-89. 672

673 White, JA, \& Keller, BL. 1984. Evolutionary stability and ecological relationships of 674 morphology in North American Lagomorpha. Special Publication, Carnegie Museum Natural 675 History, 9, 58-66.

676

677 Wible JR. 2007. On the cranial osteology of the Lagomorpha. Bulletin of Carnegie Museum of 678 Natural History 39: 213-234.

679

680 Wroe, S., and Milne, N. (2007). Convergence and remarkably consistent constraint in the 681 evolution of carnivore skull shape. Evolution, 61(5), 1251-1260.

682

683 Zhang, Z. G., and D-Y, Ge. 2014. Postnatal ontogenetic size and shape changes in the craniums 
684 of plateau pika and woolly hare (Mammalia: Lagomorpha). Zoological Research, 35(4), 287685293.

686

687

688

689 


\section{Figure captions}

691 Figure 1 - Facial tilt in leporids. The crania of Caprolagus hispidus (AMNH 54852, above) and 692 Pronolagus crassicaudatus (AMNH 89033, below) are shown in right lateral view. Facial tilt 693 (FT) is defined as the angle between the upper diastema and the occipital plane, where increased 694 values indicated a skull orientation closer the horizontal plane, and calculated in this dataset was 695 using the angle between landmarks 43, 1 and 7 (see Fig, 2). Modified from Kraatz et al. 2015.

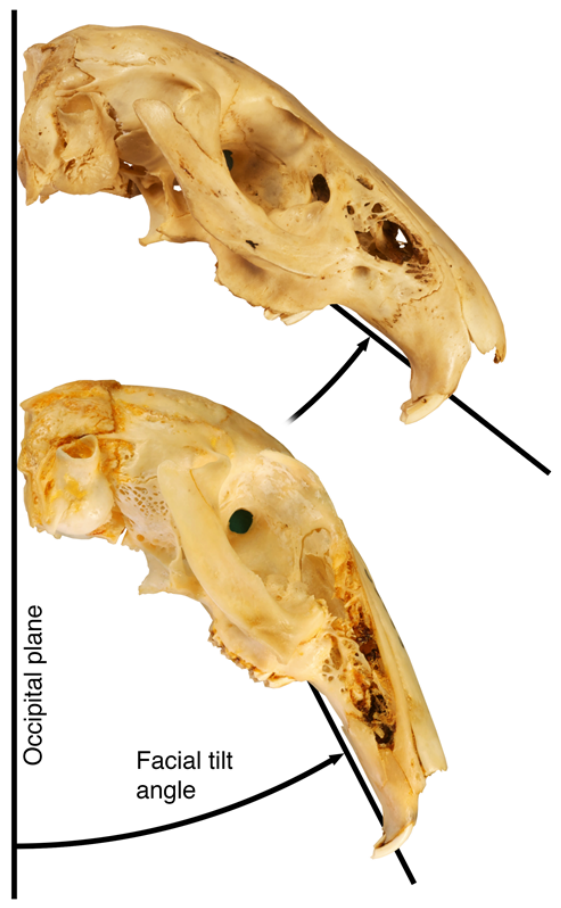

697

698

699

700

701

702

703

704

705 
706 Figure 2 - The 52 landmarks used in this study to characterize cranial shape. Landmarks 43, 1 707 and 7 are marked in red in lateral and posterior views. See Table S3 for detailed explanation of 708 landmarks.
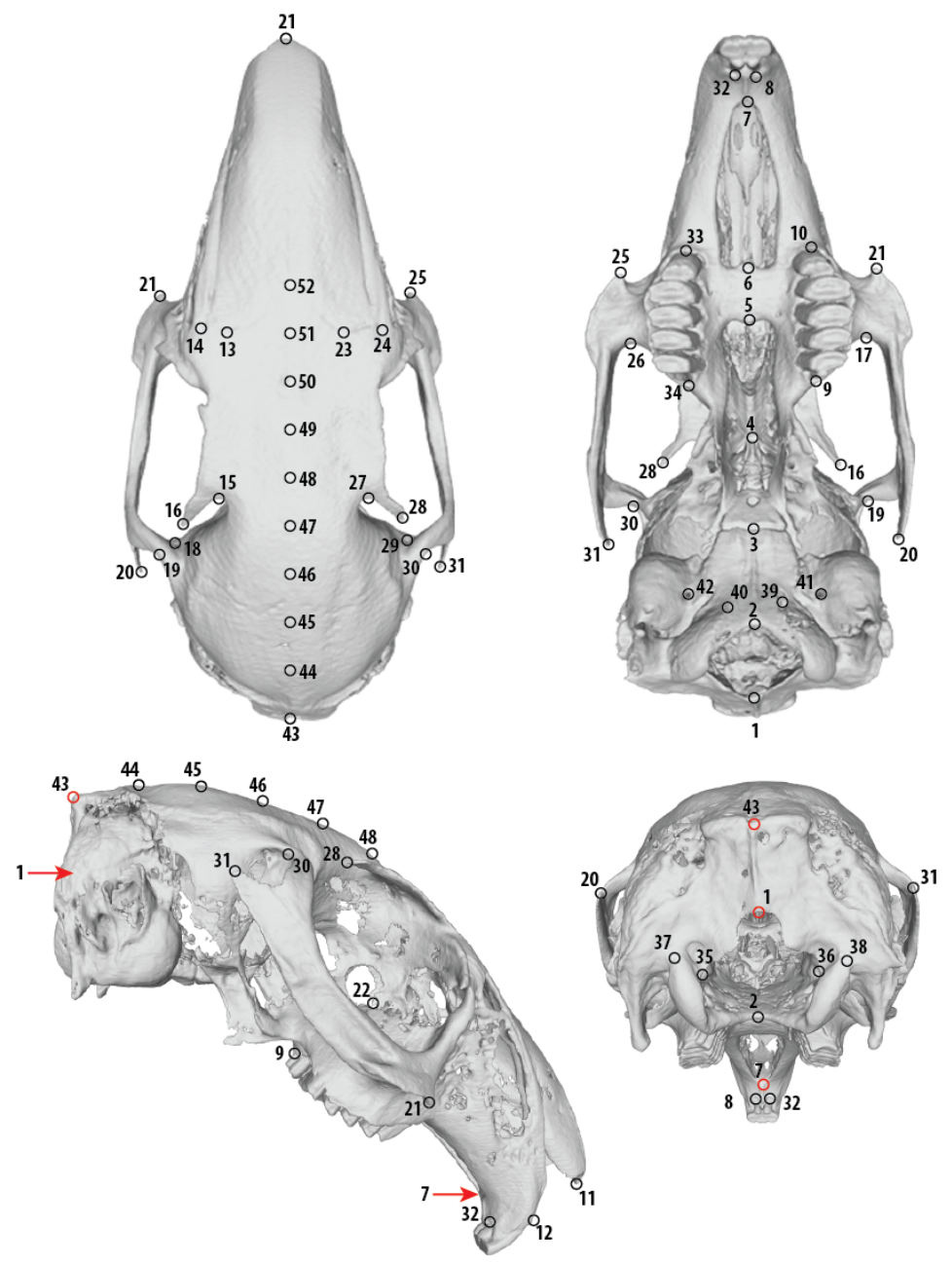
710 Figure 3 - The leporid cranial morphospace and phylomorphospace. The first three principal

711 component (PC) axes from a PCA of 184 individual crania representing 20 species (A). The first

712 three PC axes from a PCA of 20 species averages with the phylogeny of Mathee et al. 2004

713 projected into the shape space (B). Three distinct morphogroups can be distinguished. The

714 legend provides a key to shapes and colors plotted in A and B. Shapes in B are scaled to average

715 centroid size (1/80). Genus abbreviations in legend can be referred to full species names in Table 7161.

717
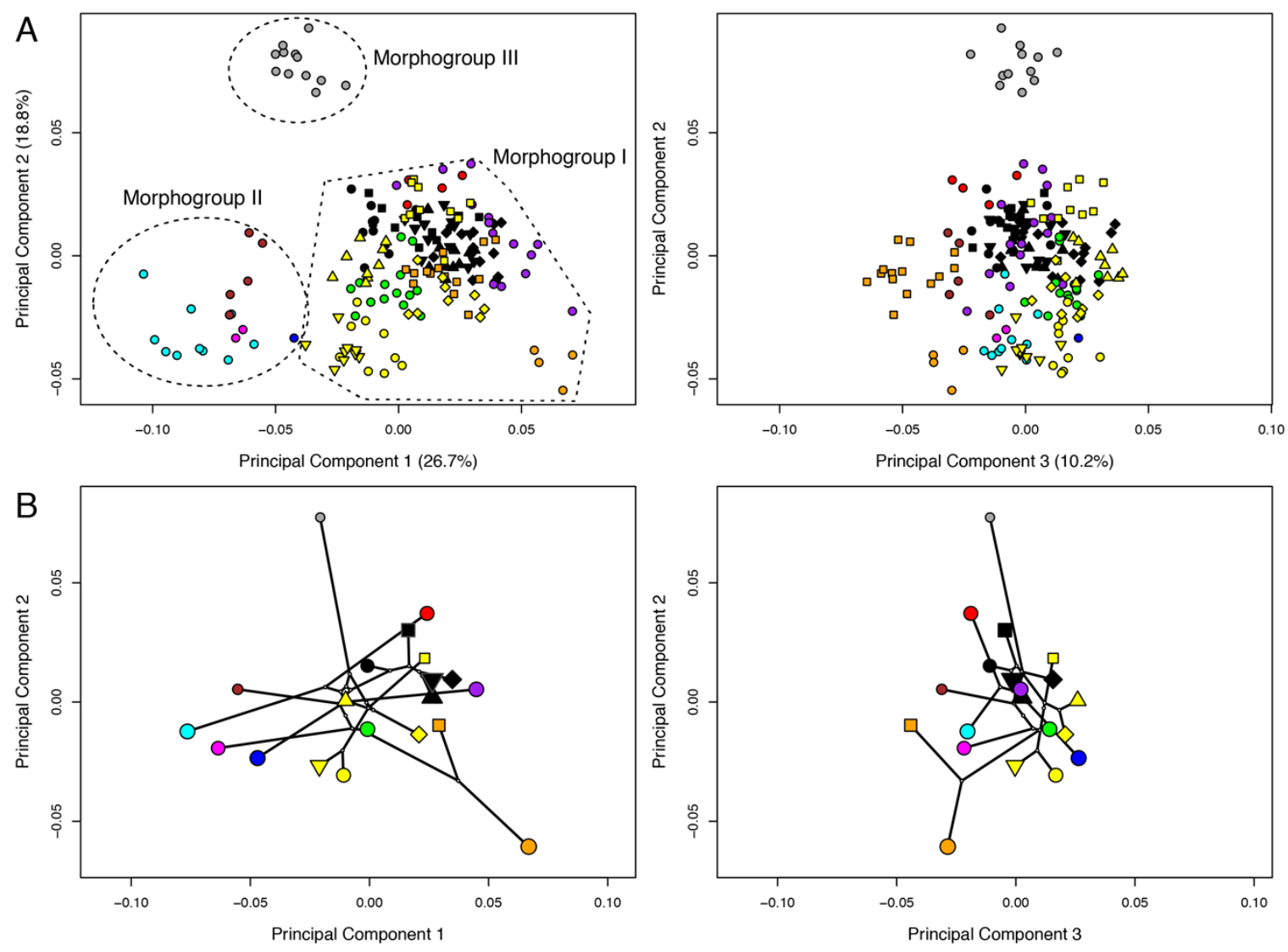

718
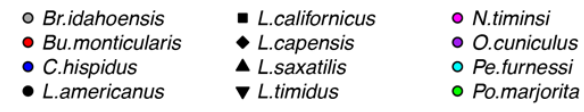

- Pr.randensis

- Pr.rupestris

- R.diazi

$\square$ S.audubonii

$\diamond$ S.floridanus

$\Delta$ S.obscurus
$\nabla$ S.palustris 
719 Figure 4 - The three main axes of shape variation in Leporid crania, as described by PCA of 184 720 specimens (Figure 3A), visualized by warped crania surfaces. Crania are shown in lateral, ventral 721 and dorsal views (top, middle, bottom, respectively), in two columns representing the shape

722 change from the mean to the minimum value of the PC axis (left, denoted by a minus sign), and 723 the shape change from the mean to the maximum value of the PC axis (right, denoted by a plus 724 sign). Warping was done using thin-plate spline method (see methods for details). Lateral views 725 were aligned along the occipital plane.
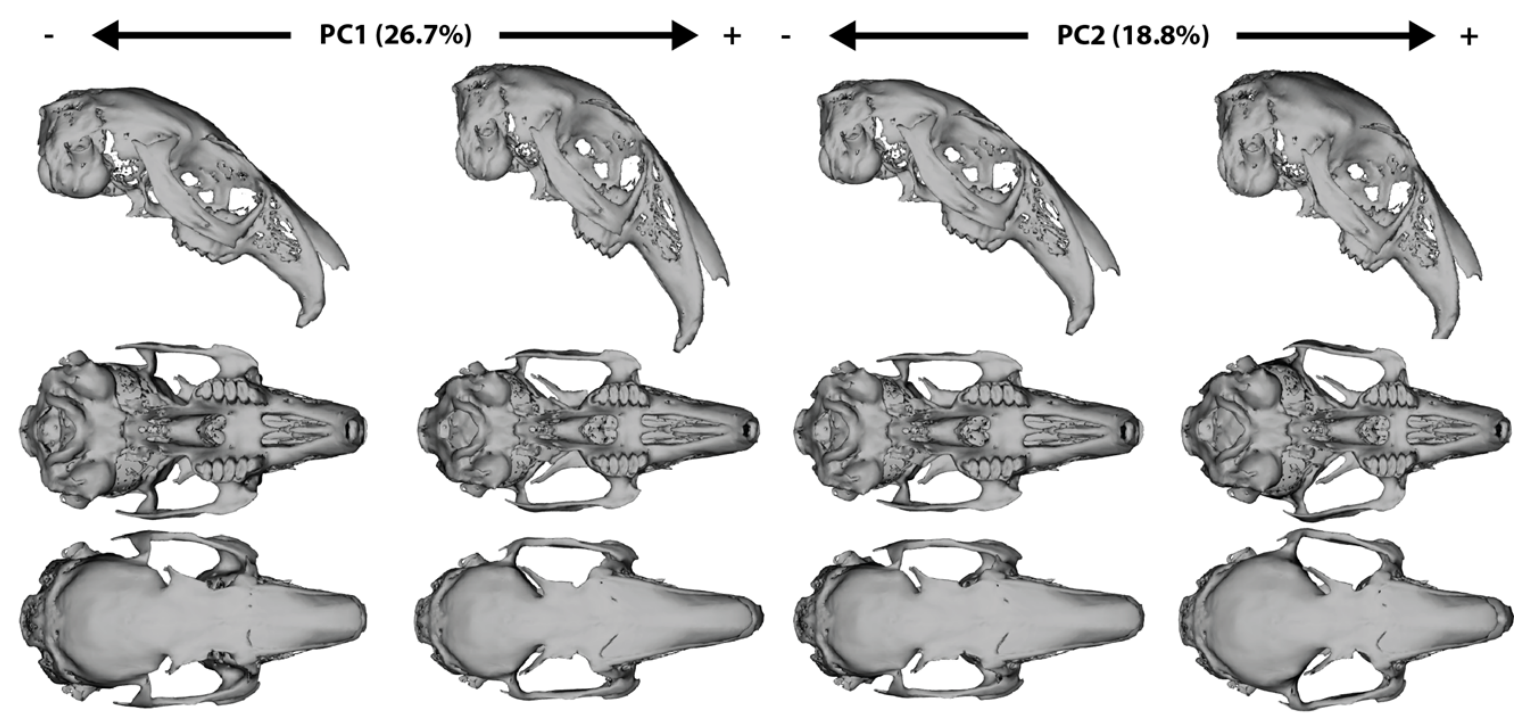

726
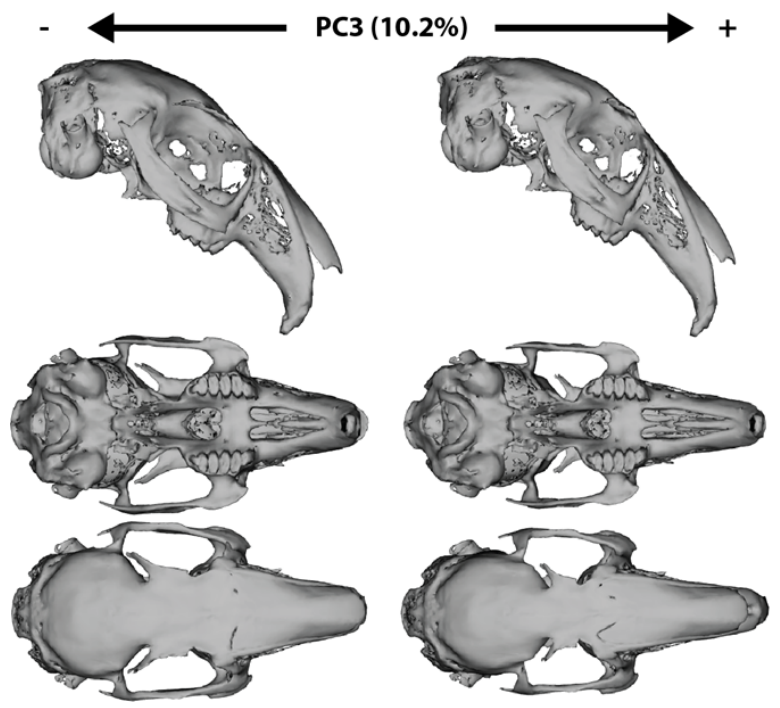

727 
728 Figure 5 - Summary of the relationship between locomotory mode and facial tilt, against the 729 Matthee et al. 2004 phylogeny. Facial tilt angle $\left(^{\circ}\right)$ is plotted alongside the phylogeny (right). The

730 boxes and midline represent the lower and upper quartiles (25\% and 75\%) and median of the

731 facial tilt angle, colored by locomotory mode. A low angle represents a highly tilted cranium, as

732 demonstrated by the silhouette crania (top right). Right inset: a summary of facial tilt angle for

733 each locomotory modes. Left inset: the cranial shape morphospace (as in Fig. 3A) is shown,

734 colored by locomotory mode. See Supplementary Figures 5 and 6 for detail.

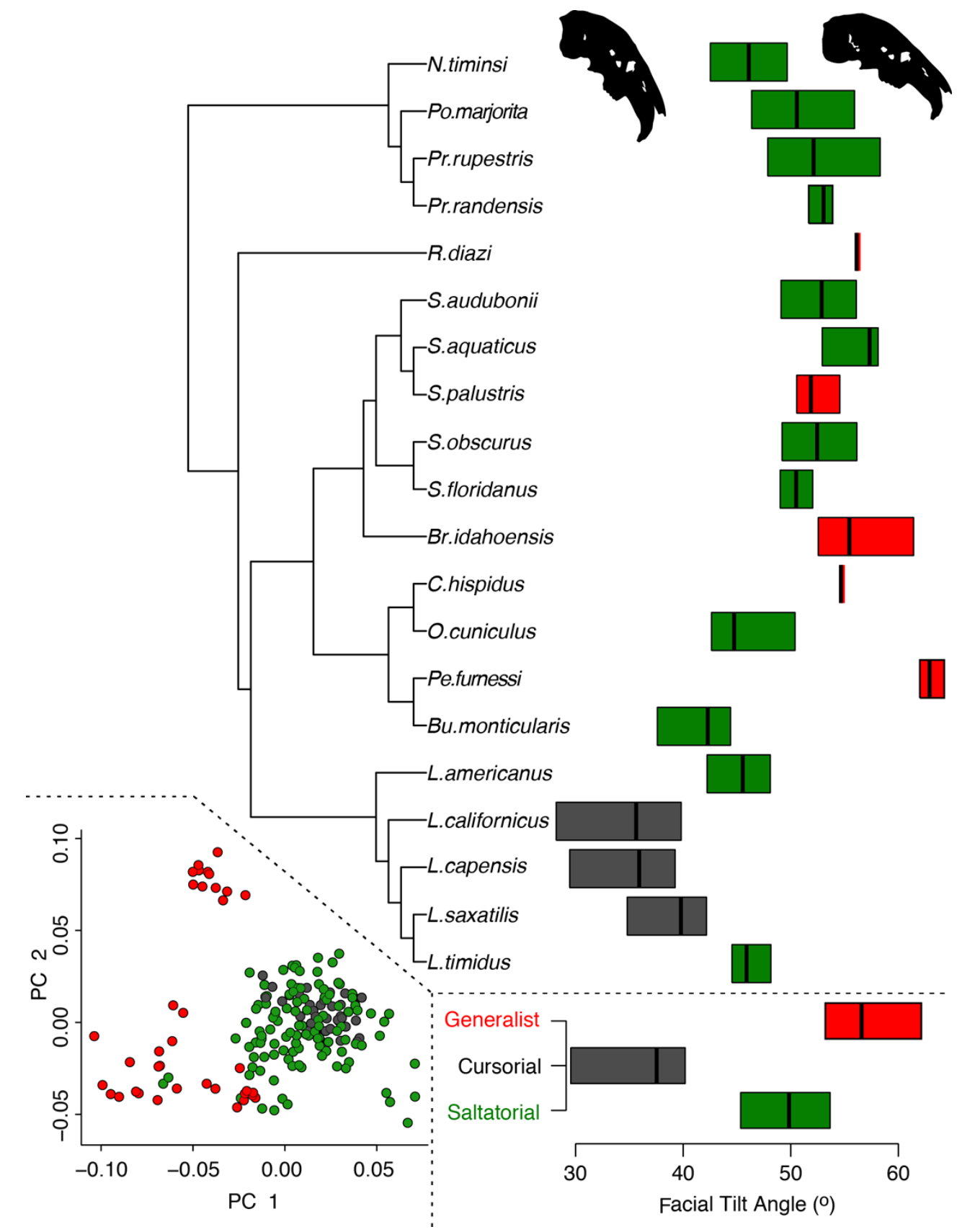


736 Figure 6 - The relationship of cranial shape to facial tilt angle, as shown with a multivariate 737 regression. Cranial shape predicted by facial tilt angle is summarized as a regression score (sensu 738 Drake \& Klingenberg 2010). Specimen points are denoted as in Fig. 3A. The warped crania on 739 the left represent the predicted shape at the highest facial tilt angle (top), which corresponds to a positive regression score, and lowest facial tilt angle (bottom), which corresponds to a negative

741 regression score.

742

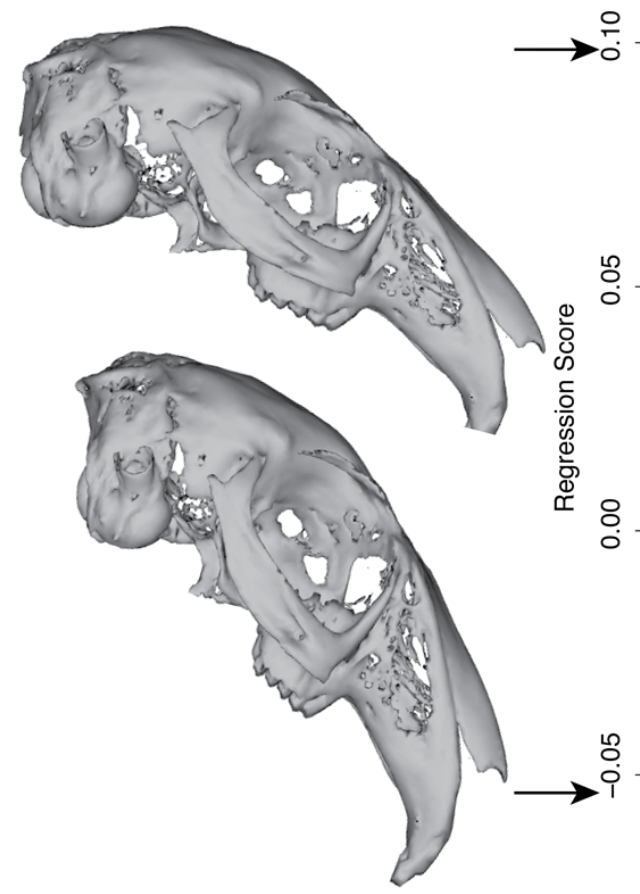

743

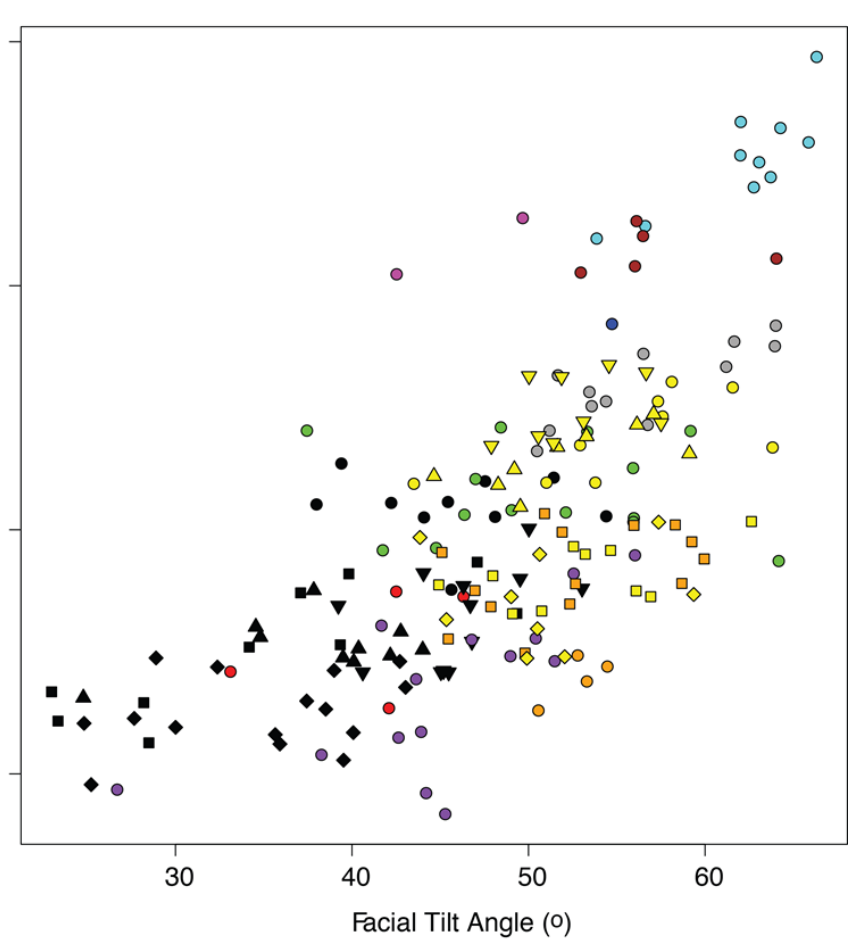


744 Figure 7 - Lateral views of fossil and extant species that represent the likely cranial

745 macroevolutionary history of Lagomorpha, evolutionary relationships discussed in Kraatz et al.

746 (2010). Crown Leporidae is represented by minimum and maximum surface warp

747 transformations of PC1 (this study); stem- Leporidae is represented Alilepus hibbardi (image

748 from White, 1991) and Hypolagus sp. aff. H. vetus (image from Hibbard, 1969); Ochotonidae is

749 represented by the only living genus, Ochotona; stem lagomorphs are represented by the late

750 appearing Palaeolagus (image from Wood, 1940) and early appearing Gomphos (CT scan of 751 MAE-14425). All crania are scaled to the same size.

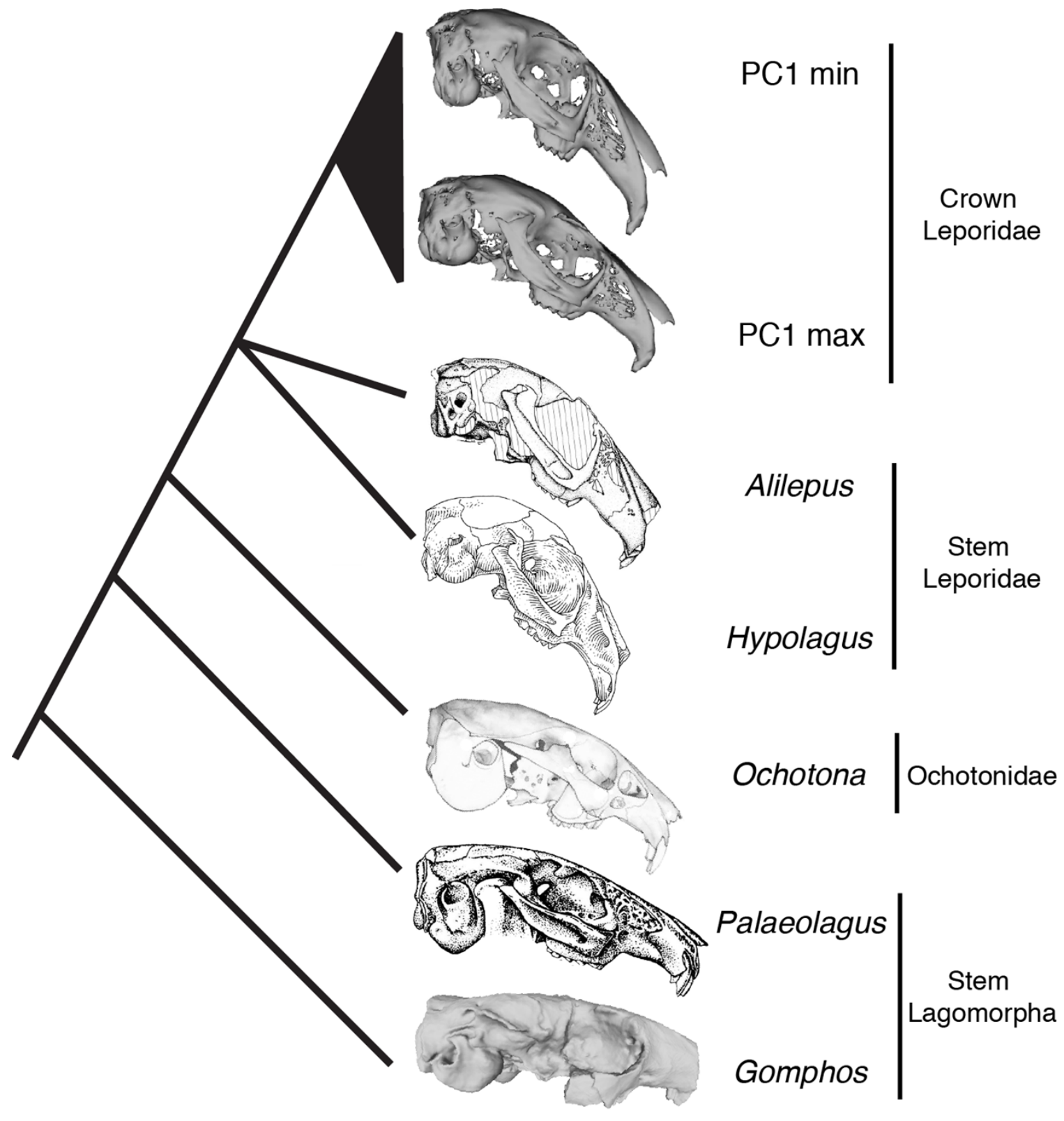

